\title{
Implicaciones de la ley general de cultura en el desarrollo educativo y cultural de la región
}

\author{
GUILLERMO SANCHEZ FIERRO**
}

Ponencia elaborada y leída por el autor en el Foro Regional de Cultura organizado por el Ministerio y el Instituto Huilense de Cultura, en Octubre de 1997 en la Ciudad de Neiva.

Q uiero en la presente intervención abordar de manera breve cuatro aspectos: En primer lugar, una ilustración sobre nuestras raíces e identidad cultural. En segundo lugar, una reflexión sobre implicación de la identidad y el compromiso personal e institucional en el desarrollo educativo y cultural. En tercer lugar, algunos aspectos generales sobre la ley de cultura y en cuarto lugar, plantear unos requerimientos y compromisos institucionales mínimos para lograr la operatividad de la ley.

\section{Sobre identidad cultural:}

A manera de ilustración, quiero referirme al Maestro Nicolás Buenaventura, quien en su "Homenaje a la opititud", nos dice:

Jefe del Departamento de Artes - Universidad Surcolombiana.

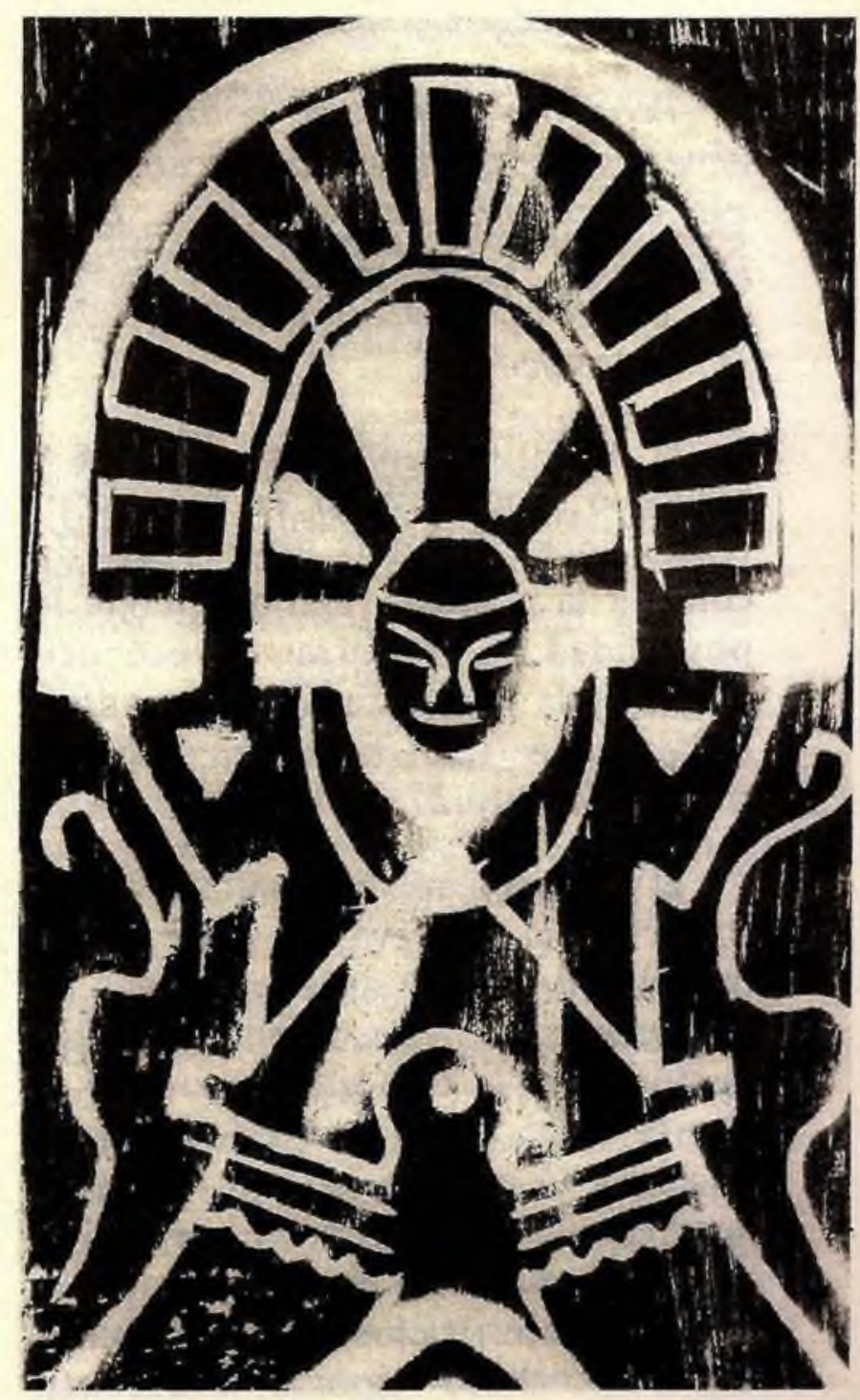

llustración: Alexander Salazar 
"Cuando pienso en el Huila, el alma misma del Huila, asocio este pensamiento a la leyenda de un pájaro extraño que volaba hacia atrás, al revés de todas las aves. $Y$ una vez vino el buiho, que es caviloso y anda buscando la razón de todo, vino y le preguntó por qué solía volar de esa manera, a lo que el animal le respondió, vuelo hacia atrás porque me importa más de donde vengo que hacia donde voy.

De seguro no existe ningún pueblo, ninguna cultura humana, que no tenga su parecido con este pájaro, ninguno que sea capaz de definir su rumbo, de aclarar su horizonte, sino sabe claramente de donde viene.

Pero en el caso de la "opititud", del alma huilense, me ha parecido siempre que este compromiso de la identidad, con su propia raiz, con su "saber de donde vengo", es algo que pesa mucho, algo particularmente valedero".

El hecho de habitar en el Huila y pensar o suponer estar en otros contextos socioculturales, nos separa de conocer la realidad regional, limita la posibilidad de encontrar el reconocimiento y la identificación con el Huilense a quien rinde homenaje el maestro Buenaventura.

El desconocimiento de una realidad sociocultural, conlleva a la imitación de modelos de vida y de expresiones, al consumo masivo y desordenado de productos, pero lo mas grave de esto, es que se limita el desarrollo de la imaginación y la creatividad para realizar aportes que contribuyan a la solución de problemas sociales, educativos y culturales aterrizados, es decir aplicados a la realidad regional, local, institucional y profesional.
Sin caer en el "folclorismo" o "regionalismo" y menos en el "parroquialismo" como muchos creen que puede suceder cuando se considera a la opititud como objeto de estudio; es posible que este homenaje a nuestro pueblo, nos sirva de apoyo para realizar una reflexión sobre el compromiso con nuestra familia, el barrio, la ciudad, el trabajo, la educación, los valores y todas las relaciones socio-culturales en las cuales participamos cotidianamente.

Digo esto, por que no podemos continuar viviendo con los pies y el cuerpo en esta tierra, pero con los ojos y el cerebro, mirando y pensando en intereses y valores de otros contextos socio culturales.

Implicaciones de la ley de cultura para el desarrollo regional

La importancia de cualquier norma en un contexto, depende del nivel de aplicación que los funcionarios hagan de ella. Pero la aplicación también depende de varios factores, entre otros, el de la identidad cultural, que conlleva al compromiso con que cada funcionario asuma su función social.

Sobre identidad y compromiso, me permito solicitar atención a los siguientes interrogantes:

1. ¿Nos identificamos y comunicamos los padres de familia con las generaciones anteriores (padres y abuelos) y con las generaciones posteriores (hijos y nietos) para dialogar sobre potencialidades, aportes a la humanidad y valores culturales de cada generación?.

2. ¿Los empleados, trabajadores, funcionarios y profesionales, nos identi- 
PAIDEIA

vos de la institución o empresa a la que pertenecemos?

3. ¿Será que las potencias económicas internacionales y nacionales, identifican y respetan la cultura, los valores y derechos humanos de nuestro país y nuestra sociedad a quienes han convertido en asiduos consumidores de sus productos?

4. ¿Se identifican y cumplen, entre otros, el político, el médico, el abogado, con el juramento realizado el día de su grado, su posesión o los compromisos adquiridos en su campaña electoral?

5. Por último ¿Nos identificamos y estamos verdaderamente comprometidos en detectar y presentar propuestas de solución a los problemas sociales de nuestra casa, vecindad, barrio, vereda, pueblo, ciudad, departamento, país y el mundo.

Dejo estas inquietudes para la reflexión de cada persona con el convencimiento que de su análisis profundo se obtendrán respuestas para el mejoramiento de nuestro entorno económico, político y sociocultural.

\section{Elementos generales sobre la ley de cultura}

Mirando los contenidos de la ley y los textos donde están recopiladas las ponencias de los foros realizados previamente a la creación del Ministerio, he podido detectar que allí se encuentran registrados:

1. Los principios fundamentales y los derechos sociales y culturales enunciados por la Constitución Nacional y la Ley General de Educación.
2. La vasta experiencia de Colcultura, en la organización y realización de programas de promoción y estímulo a la creación, la interpretación y la formación artística y cultural.

3. Los valiosos aportes de personalidades del orden Nacional e Internacional, quienes desde su especialidad (cultura, artes, crítica, educación, política, economía, etc) participaron en la causa cultural de nuestro país.

Estos aspectos y elementos, como componentes de la ley, son suficientes para comenzar un desarrollo educativo y cultural en Colombia, siempre y cuando se haga aplicación acorde con las necesidades y características de cada contexto.

Algunas estrategias y compromisos institucionales para el desarrollo educativo y cultural

Fundamentado en la búsqueda de identidad y la recuperación de valores socio- culturales que posibiliten un verdadero compromiso con el departamento, me permito presentar a consideración las siguientes estrategias:

Primera: Programación y realización de jornadas pedagógicas para todos los municipios sobre la ley General de Cultura y al mismo tiempo, realizar un diagnóstico sobre fortalezas y debilidades del potencial investigativo, ed Icativo, artístico y cultura regional. Para abordar este aspecto, pueden vincularse, instituciones culturales y diferentes unidades de la Universidad Surcolombiana, como el Departamento de Sicopedagogía, el Instituto de Investigaciones, el Departamento de Artes, los Programas de Español, Comunicación Social y Periodismo entre otros, los cua- 
les cuentan con una extensa trayectoria en los campos de la educación artística, la pedagogía y la investigación socio-cultural.

Segunda: Con base en el diagnóstico de la situación y con la participación de la comunidad académica, artística y cultural regional, diseñar un plan de desarrollo educativo y cultural para el Huila. El Programa de Administración Educativa, cuenta con un equipo docente investigador preparado en planeación educativa y cultural que puede asumir esta tarea, tal como ya lo ha venido implementando en algunas localidades del departamento.

Tercera: Que los programas de educación, de estímulos a la creación y el desarrollo de actividades, cubran todo el Departamento del Huila y se incluyan todas las disciplinas artísticas y culturales. Para ello se requiere el compromiso de los directivos de las Instituciones de Cultura y Educación del orden Departamental y Municipal, los Fondos Mixtos y la colaboración del equipo docente del Departamento de Artes, de los postgrados en Creatividad para la docencia y en Creación Literaria de la Universidad Surcolombiana, entre otros, desde donde se pueden elaborar criterios, propuestas y programas para el desarrollo del arte y la cultura regional.

Cuarta: Realizar una representativa y justificada inversión en instrumentos y equipos, bibliografía y recursos didácticos para la educación artística y cultural. Dentro de los planes de desarrollo debe contemplarse la educación artística en las modalidades no formal y continuada. En tal sentido, los esfuerzos realizados por instituciones como: El Conservatorio Departamental, el
Plan Batuta y las Escuelas Artísticas de las organizaciones no gubernamentales deben ser apoyadas para que puedan cubrir con eficiencia y en óptimas condiciones a un alto volumen de estudiantes de todas las edades y sectores sociales.

Quinta: Convocar de manera democrática y participativa para la elección de miembros a los Consejos Directivos de Cultura y evaluar su desempeño de manera periódica para cumplir con los procesos de cualificación permanente y su aplicación a los requerimientos del medio artístico y cultural regional y local.

Sexta: Convocar a la concertación inter-institucional para realizar programaciones educativas y culturales integradas. Esto permite mayor difusión y asistencia del público por cuanto todas las instituciones estarían difundiendo y convocando la actividad cultural desde diferentes escenarios durante todo el año.

Considero, que creando espacios para que participe y se escuche la comunidad artística, educativa y cultural, aparecerán mas sugerencias para enriquecer esta propuesta y se construyan proyectos educativos que propendan por un real desarrollo educativo y cultural regional.

Creo finalmente, que con un poco de voluntad gubernamental ,local, regional y nacional, se pueden atender como mínimo las estrategias anteriormente planteadas, para que en su próxima visita a Neiva, le podamos decir al señor Ministro:

"El Ministerio de Cultura es una realidad, felicitaciones", luego, le brindemos el abrazo sincero del Huilense. De ese huilense que de niño, anhela encontrar un amigo para confiarle sus 
ideales; de joven; desea encontrar apo- de anciano, espera que la tolerancia, el yo y seguridad en sus hermanos de respeto por el otro y el apoyo a la vida patria chica; de adulto, quiere adquirir se conviertan en valores como ejemplo una formación humana y profesional, de convivencia pacífica, para los hijos que le permitan ser útil a su sociedad y de las futuras generaciones.

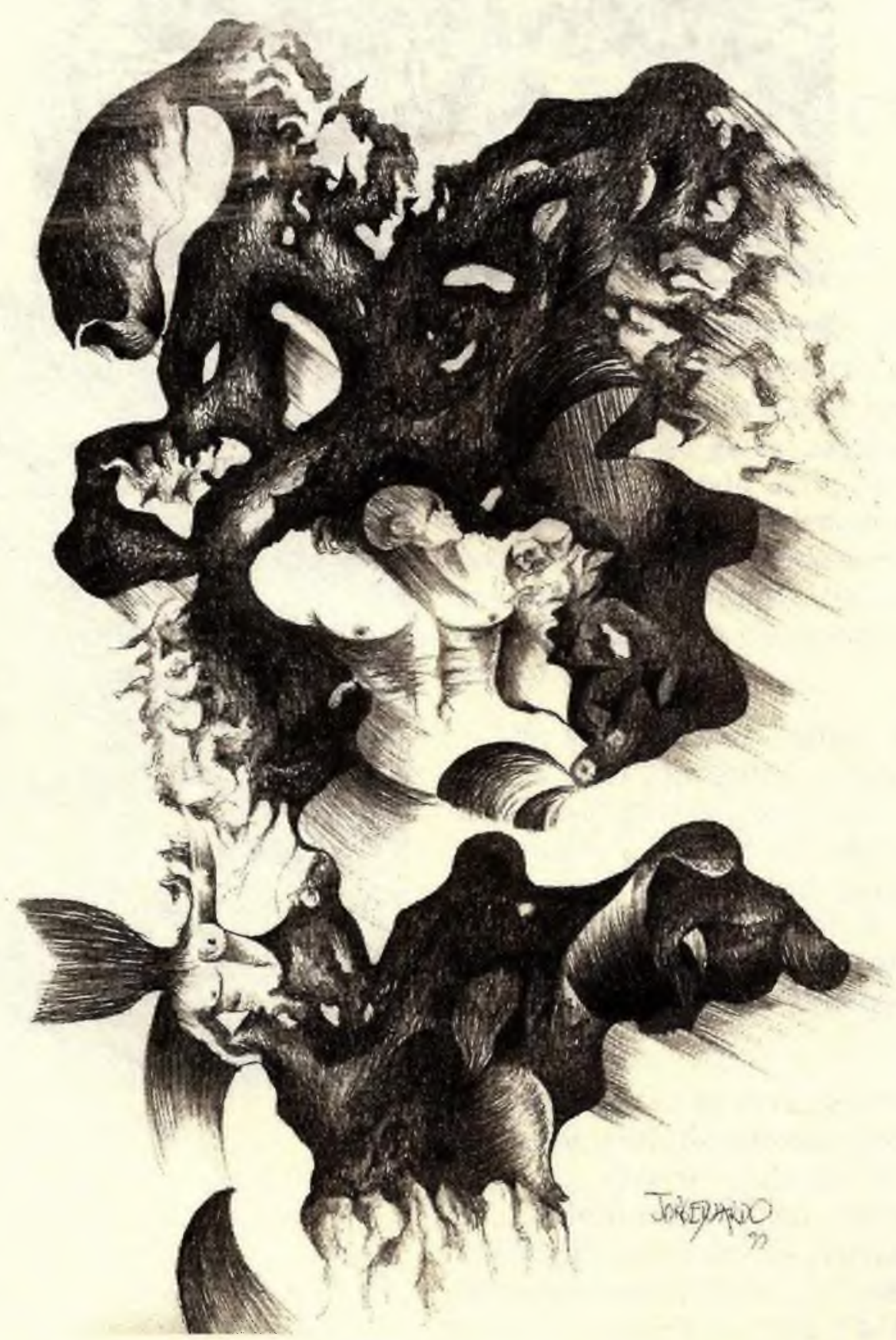

llustración: Jorge Eduardo. 


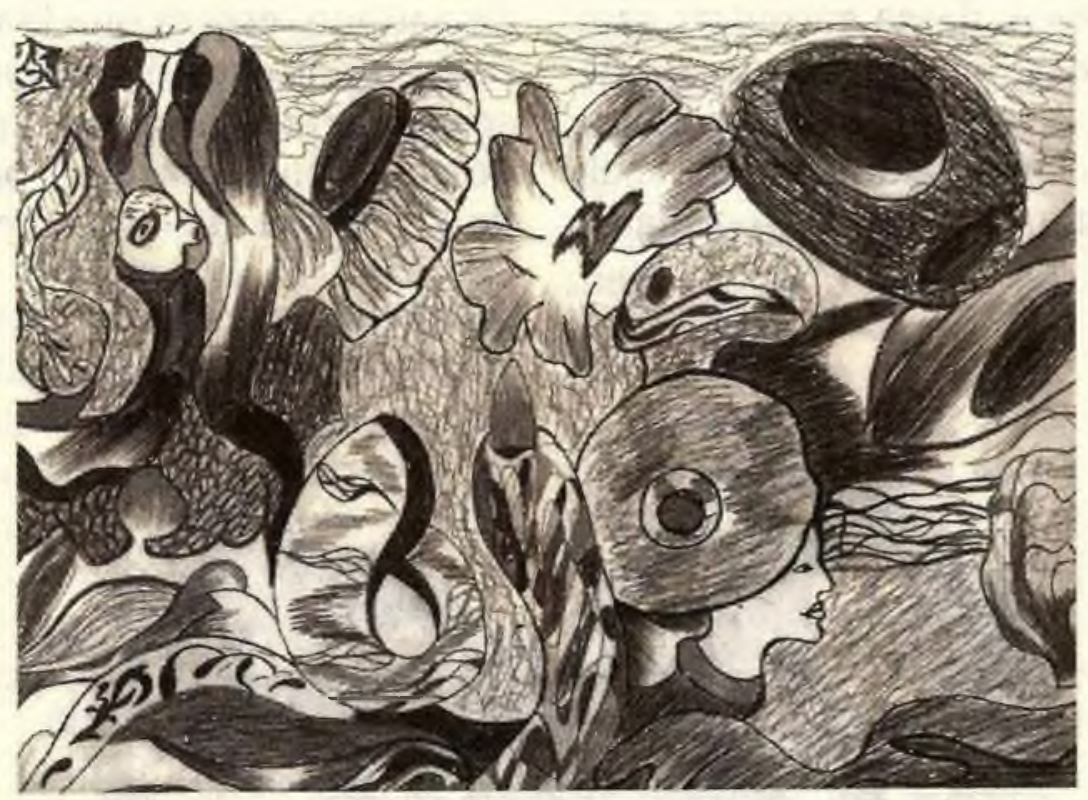

Ilustración: Luz Dary Laso Calderón 